\title{
D-Zero Signal Board Feed-Thru, Instrumentation and Hi-Voltage Boxes
}

Engineering Note \#3740.210-EN-241

Issued: February 14, 1990

Originator: Rick Luther

Checked: Al Jaques 
D-Zero Engineering Note

3740.210-EN-241

Issued $2 / 14 / 90$

\section{D-Zero Signal Board Feed-Thru. Instrumentation and $\mathrm{Hi}$ - Voltage Boxes}

\section{Al Jaques}

The three boxes being reviewed all operate at a pressure of less than $15 \mathrm{psig}$. Since they are relieved at $13 \mathrm{psig}$, they fall outside the scopes of the ASME Pressure Vessel Code, Fermilab Engineering Standard SD-37B, and Chapter 5031 of the Fermilab Safety Manual, therefore a Pressure Vessel Engineering Note showing compliance with SD-37B is not required.

In calculating the design stresses, only the largest of the three boxes, the signal board feed-thru box, was analyzed. This box had the largest spans and areas and would experience the largest pressure-related forces. The thinnest walls of each box were found to be in the top plates and they were also the side of the box which exposed the largest amount of area to internal pressure. The signal board feed-thru box top plate had at least twice the pressure area than either the instrumentation or hi-voltage boxes' top plates. This large disparity overshadows the slight difference in top plate thicknesses between the three boxes (0.56" vs. 0.25 " and $0.3125^{\prime \prime}$, respectively).

Therefore, we felt the analysis of the larger signal board feedthru box would justify the design of the smaller instrumentation and hi-voltage boxes. Appended to the end of this engineering note are the weld procedure, assembly report and the pressure test procedure \& results for the signal feed-thru box. Also, included as a reference is a list of the drawing numbers for the parts and assembly of the signal board feed-thru, instrumentation and hi-voltage boxes. 


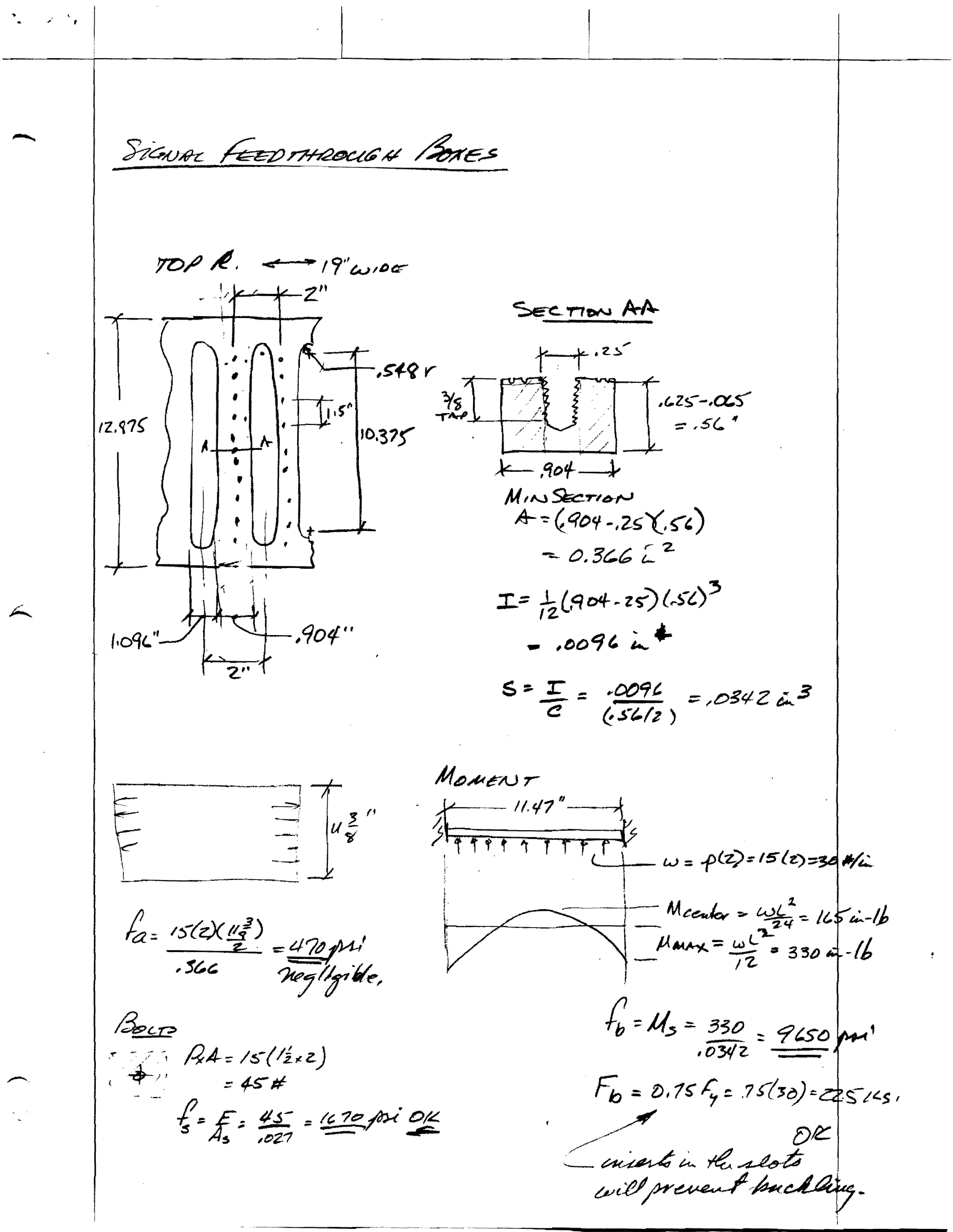




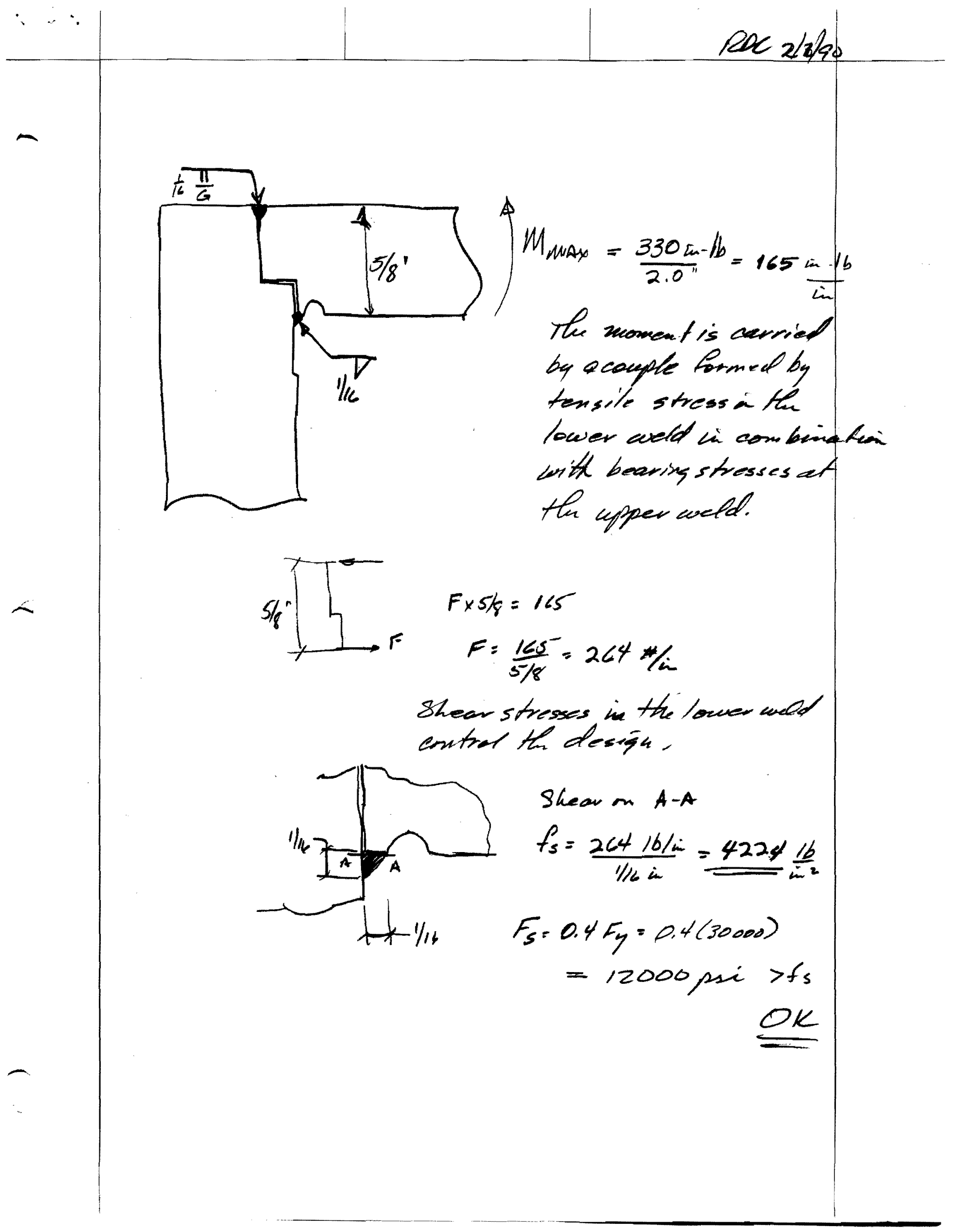




\section{Drawing \#'s \& Titles for Signal Board Feed-Thru Box}

$3740.223-\mathrm{ME}-224540$

$" \quad-E D-223283$

" $\quad$-MD-223298

" $\quad$-ME-223636

" $\quad$-MD-223637

" $\quad-\mathrm{MC}-223638$

" $\quad$-MC-223665

" $\quad$-ME-224533

" $\quad$-ME-224534

" $\quad-\mathrm{MD}-224535$

" - ME-224536

" $\quad$-MC-224539
D-Zero EC Signal Board Feed-Thru Box - Assembly

\begin{tabular}{|c|c|c|c|}
\hline " & $"$ & $"$ & -W/Seal \\
\hline$"$ & $"$ & $"$ & - Seal Block Ass'y \\
\hline$n$ & $"$ & $"$ & - Welded Unit \\
\hline$"$ & $"$ & $"$ & - Side Plate \\
\hline " & $"$ & $"$ & - Seal Clamp \\
\hline " & $"$ & $"$ & - Test Plug \\
\hline$"$ & $"$ & $"$ & - Top Plate \\
\hline " & $"$ & $"$ & - Bottom Plate \\
\hline " & $"$ & $"$ & - End Plate \\
\hline " & $"$ & $"$ & - Side Flange \\
\hline " & $"$ & $"$ & - End Seal Clamp \\
\hline
\end{tabular}


Drawing \#'s \& Titles for High-Voltage Box

$3740.515-\mathrm{ME}-255662$

D-Zero CC High-Voltage Box Assembly

". $\quad$-MD-255663

" $\quad$ MD-255664

" $\quad-\mathrm{MC}-255665$

" $\quad$-MC-255666

" $\quad-\mathrm{MC}-255667$
" $\quad$

1"

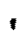

" - Dbl. Seal Top Flange

" - Bottom Plate

" - Side Plate

" - Front Plate

" - Top Plate

Drawing \#'s \& Titles for Instrumentation Box

3740.515-ME-224803

" $\quad-\mathrm{MD}-224805$

" $\quad$ MC-224806

" $\quad$-MB-224807

" $\quad-M B-224808$

" $\quad$-MB-224809
D-Zero CC Instrumentation Box Assembly

,
" - Top Flange

" - Bottom Plate

" - Top Plate

" - Front Plate

" - Back Plate

" - Side Plates 


\section{SIGNAL FEGDTHRU BOX WELD PROCEDURE}

3740.210-EN-123

BOB FERRY NOVEMBER 12,1987

1. Firmly bar clamp the bor together in all directions. When all directions have been secured, tack weld each outside seam of the box in 4 or 5 places $P K(<C E-1)$

along it's length. Remove clamps and procede to weld all outside seams. Care

should be taken that maximum weld cross section does not exceed $1 / 16^{\prime \prime}$ I $1 / 16^{\prime \prime}$.

2. To help stabilize the metal as it cools we will install all slot plugs,.(.MC223665), and one side cover plate,( MD-223637). Inside welds for this side Mion...

plate will be done thru the opposite side flange. Weld cross sections should be held to a 1/16" maxium depth and width.

3. Weld the inside of the end plates, (MD-224535), using the weld relief as filler material. After the bor has cooled,weld the top plate(ME-2244533) to the side flange( $M E-224536$ ) and then to the bottom plate(ME-224534).

4. Repeat this procedure for the opposite side.

5. Helium leak check the welds, inside and out, by plugging the slot pumpout holes and pumping on the pump out line. Remember that the clearances are very tight in the space that is to be pumped. Allow plenty of time for a good pumpdown and leak check. Leak detection shohld be on the most sensitive scale on a helium leak detector with a minimum sensitivity of 10E-9 ATM CC/SEC.

6. See 30 psig. pressure test procedure.

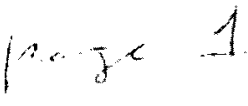




\section{PROTOTYPE SIGNAL FEEDTHRU BOX *2}

\section{ASSEMBLY REPOR'T BOB FERRY NOV. 111987}

Upon delivery of the 8 machined plates they were inspected for any deviations from the detail drawings. All measurements made were within the set tolerances and they were submitted for welding.

Welding of the plates falls into two catagories, Øutside fusion welds, and inside fillet welds. Because fillet welds require more heat and longer time spent in any given place, these are the most critical. As in all of our applications using 304 Stainless Steel a 308L filler rod was used.

The box was clamped together to check fit and that all joints as expected. A learned group of indivduals was then assembled to discuss the technique for best welding results. All concured that weld reliefs on the inside of the box would be the safest method for reducing the warp due to contraction of the cooling weld area. It was also noted that some of the plates had been drawn with $1 / 16$ " chamfers on the edges. We will rework these by building up weld material then remachining to sharp 90 degree edges. Revised drawings were generated removing the chamfers and adding $1 / 16^{*}$ x $1 / 16^{\prime \prime}$ weld reliefs to the end plates.

Reasse mbly of the box took place on November 9 and welding began that afternoon. Welding was done by the weld procedure attached to this memo. During the leak check which followed three small leaks were detected, all in corners. After all leaks were repaired the box was sucessfully pressure tested to 30 psig.

$$
\operatorname{lig} 2
$$




\section{SIGNAL FEEDTHRU BOX PRESSURE TEST}

3740.210-EN-123

Bob Ferry November 13,1987

On November 14,1987 a pressure test of the prototype II Signal

feedthru box was performed. The following is a description of how this test 7 itiz

was performed and what results obtained. The people conducting the test were jim Harder and myself.

1. A completed Signal feedthru box is outfitted with it 's standard side plates, drawing number MD-223637. The indium seals are not installed for this test. A full set of slot plugs, drawing MC-223665, are installed into the top plate of the box. During this pressure test the indium and the 0 ring seals are installed. By doing this now I am able to do a complete leak check of the slot pumpouts and the captured weld area before and after the pressure test.

2. A bottom plate was fabricated using the same drawing as the final assembly flange which is used on the $\mathrm{CC}$ cryostat. This drawing number is ME-223235 sheet 3 of 8 view BB. Some obvious exceptions suould be noted a. The $C$ seal groove is omitted.

b. The plate was made as a blank and not a flange.

c. a 1/4" pressure tap supply port was added.

3. A test area was set up at at the RF barn and all acess to this was halted. The box was pressurized tol 5 psig. and allowed to sit for 10 minutes, at which time the box was snopped and found to be leak free. A second test at 30 psig. was also done in the same manner with no leak present.

4. The box was then measured for flatness and these numbers were within the .002 "flatness that was measured after the welding operation. 


\section{SIGNAL FGEDTHRU BOX PRESSURE TEST}

\subsection{0-EN-123}

Bob Ferry November 13,1987

On November 14.1987 a pressure test of the prototype II Signal

reedthru box was performed. The following is a description of how this test was performed and what results were obtained. The people conducting the test were jim Harder and myself.

1. A completed Signal feedthru box is outfitted with it's standard side plates, drawing number MD-223637. The indium seals are not installed for this test. A full set of slot plugs, drawing MC-223665, are installed into the top plate of the box. During this pressure test the indium and the 0 ring seals are installed. By doing this now I am able to do a complete leak check of the slot pumpouts and the captured weld area before and after the pressure test.

2. A bottom plate was fabricated using the same drawing as the final assembly flange which is used on the $\mathrm{CC}$ cryostat. This drawing number is ME-223235 sheet 3 of 8 view BB. Some obvious exceptions suould be noted a. The $C$ seal groove is omitted.

b. The plate was made as a blank and not a flange.

C. a 1/4" pressure tap supply port was added.

3. A test area was set up at at the RF barn and all acess to this was halted. The bor was pressurized to 15 psig. and allowed to sit for 10 minutes, at which time the box was snopped and found to be leak free. A second test at 30 psig. was also done in the same manner with no leak present.

4. The box was then measured for flatness and these numbers were within the .002 "flatness that was measured after the welding operation. 
Accelerator Division Permit For Safety Tests

Safety Test: SIGNAC $=E E D T H R O B O X \not Z 2$

Location of Test: RFBARU

Hazards Involved: POSS,BLE WEGDSEAm RUPTURE

Safety Precautions Taken: BOX PLACED REMOTECY FROM

THOSE PERFORMUN THETEST SOPSIL RELIEF ON CHARge THE

Time of Test 15.13 Nov/71987

Approvals (Signature and date: time of test must be within one week of signature date. All signatures must be received at least 1 working day before safety test.

Test Coordinator: R FERRY JIM HARDER Date: NOU 171987

Division Safety officer: Date:

Division Head: Date:

Special Conditions or Requirements FOCLOLE D TEST PROCEDOEE $3740.210-E N-123$

Coturt Verry

Please Note: This form is required for all tests in which there is a question of either personnel or equipment satety. 
Date: $5-12-88$

Accelerator Division Permit For Safety Tests

Safety Test: Signal Feed Thru Box $\# 3$

Location of Test: Old towed hoops Across from AP-O

Hazards Involved: Passible rupture of welded sons. bets may strip out on flanges when sunder pressure

Safety Precautions Taken: Signed Box placed inside concrete hoop. pressurizing from at side hoop. so relief is pressurriage line

Time of Test 1000 HRS

Approvals (Signature and date: time of test must be within one week of signature date. All signatures must be received at least 1 working day before safety test.

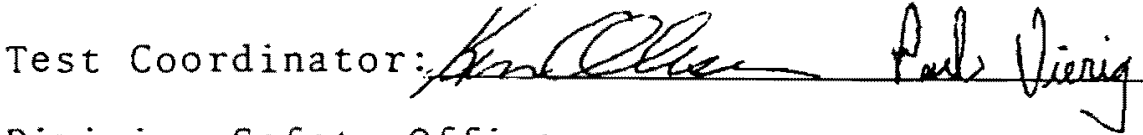

Division Safety Officer:

Division Head:
Date: $5-17-88$ Date : Date:

Special Conditions or Requirements Pressurized Box to 15 pig fer 10 min, thew snow p leak checked all seams. Pressurized to 30 pig for 10 min, depressurized and re pressurized to 30 plug for 10 min. swooped Aquino -

SEE PRESSURE TEST PROCEDURE 3740.210-EN-123

Please Note: This form is required for all tests in which there is a question of either personnel or equipment safety. 
Date: $5-17-88$

Accelerator Division Permit For Safety Tests

Safety Test: Signal Feet Thew Box 4

Location of Test: old towel hoops Across from A N-O

Hazards Involved: Possible rupture of welded reals, bolts and

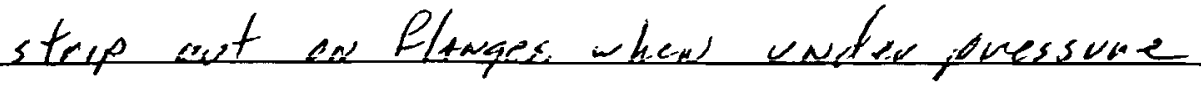

Safety Precautions Taken: Siqual Box placed inside concrete hoop, pressurizing from outside of hoop se relief in gersumizing live.

Time of Test OQ15 H ns

Approvals (Signature and date: time of test must be within one week of signature date. All signatures must be received at least 1 working day before safety test.

Test Coordinator:

Paul Veering. Date: $5-17-88$

Division Safety officer:

Date:

Division Head:

Date:

Special Conditions or Requirements Pressurized Bax to 15 sig Lar 10 min, then swoop leak check all sears. Pressurized to 30 psis for 10 mind depressurized and cepressureed to 30 psia for 10 min.

swooped again

SEE PRESSURE TEST PROCEDURE $3740.210-E N-123$

Nov $13 \quad 1987$

Please Note: This form is required for all tests in which there is a question of either personnel or equipment safety. 
Date: $10-5-86$

Accelerator Division Permit For Safety Tests

Safety Test: Squad Havel fred thru Bax $\# 5$

Location of Test: Old tun vel heaps across from $A P-O$

Hazards Involved: Possible rupture of welded sean: bolts may strip out on flanges when under pressure

Safety Precautions Taken: Signal Box placed wise concrete hoop. pressurising from outside of top

in pressurizing live

Time of Test

Approvals (Signature and date: time of test must be within one week of signature date. All signatures must be received at least 1 working day before safety test.

Test Coordinator: Date: $10 / 6 / 28$

Division Safety Officer: Date:

Division Head: Date:

Special Conditions or Requirements pressurized box to 15 prig for $10 \mathrm{~min}$. then swoop leak check all spans. Pressurize to 30 p sig - for 10 min depressurize and repressurize to 30 psia for

- 10 min. swoop satin

Please Note: This form is required for all tests in which there is a question of either personnel or equipment safety. 
Date: $14-3-80$

Accelerator Division Permit For Safety Tests

Safety Test: Signal Board feed thew Max \#6

Location of res: Old tunnel hoer Across fem AP-O

Hazards Involved: Possible rupture of welded seams, bolts mop strip out on Hinges whew wader pressure

Safety Precautions Taken: Signal box placed inside concrete hoop pressurizing from outside of hoop 45 \# rete in pressurieriagline

Time of Test

Approvals (Signature and date: time of test must be within one week of signature date. All signatures, mus be received at least 1 working day before safety test.

Test Coordinator: Date: $10 / 6 / 8 e$ Division Safety officer: Date:

Division Head: Date :

Special Conditions or Requirements pressurized box to 15 pig for 10 min. then swoop lek check all seams. Pressurized to 30 prig for $10 \mathrm{~min}$ depressurized ave repressurized to 30 prig for 10 min, sweep 47 a in.

Please Note: This form is required for all tests in which there is a question of either personnel or equipment safety. 


\section{Fermilab}

EXHIBIT B

Pressure Testing Permit*

Date:

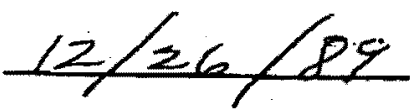

Type of Test: $\square$ Hydrostatic. $\bigotimes$ Pneumatic

Test Pressure: 32 psig

Maximum Allowable Working Pressure: 15 psig

Items to be Tested: Hip Voltaqe Feed thro Boy,

Location of Test: $\sum_{A} \leq T$ Bos reR Toafr Date and Time: $12 / 27 / 89$ Hazards Involved: $30 p=19$ Arorat GAs. Press.

Safety Precautions Taken: Test Nside can, whech Is loctiod inside welding hoodo Personple loceted outside weldiug hood. Special Conditions or Requirements:

Test coordinator: Fred WA Division/Section Safety officer:R.K. Fus Division/Section Head: G. Degan.

Dept/Date: $12 / 26 / 28$ Dept/Date: $12 / 26 / 89$ Dept/Date: $12 / 26 / 89$ Results: Tested ok.

Witness: $\frac{\text { Sor }}{\text { (Safety } \text { te ifficer or Designee) }}$ Dept/Date: AD/Soffy $12 / 27 / 89$ ) *Must be signed by division/section safety officer and division head prior to conducting test. It is the responsibility of the test coordinator to obtain signatures. 
Fermilab

EXHIBIT B

Pressure Testing Permit*

Date:

$\epsilon$

a

Type of Test:

Test Pressure:
Hydrostatic 48
Pneumatic

Maximum Allowable Working Pressure: 32 prig

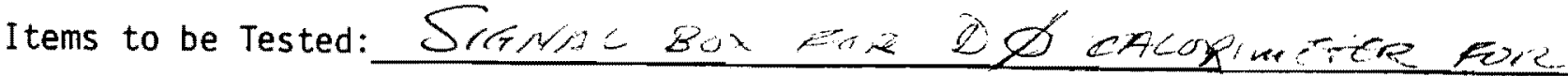

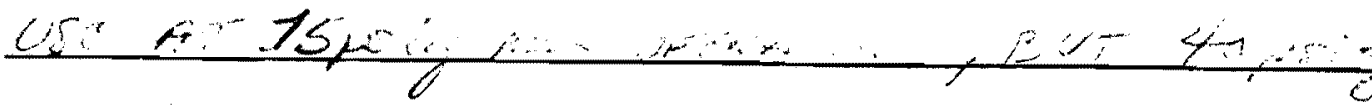

Location of Test: ERocster lower Date and Time: $6 / 15 / 90,3: 35$ PM Hazards Involved: High velocity water due to trapped air pockets depressurizing.

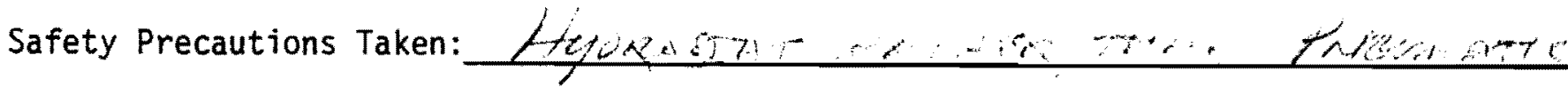

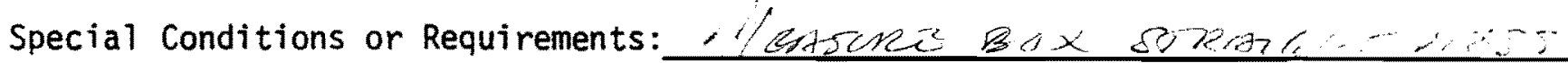

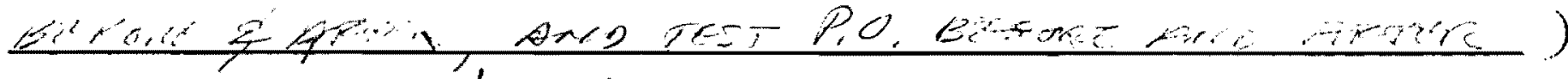

Test Coordinator: Dept/Date: $6 / 19 / 90$ Division/Section Safety/Bffiter $\mathbb{E} \alpha$ Fleam Dept/Date: RD/Safehy $6 / / 9 / 10$. Division/Section Head: Choulan P AB Dept/Date: RDO 6/19190 Results: No inelastic deformations observed at wax pressure or after depressurization. Had small pinhole leak through gasket pampont space due to leah past indium seal

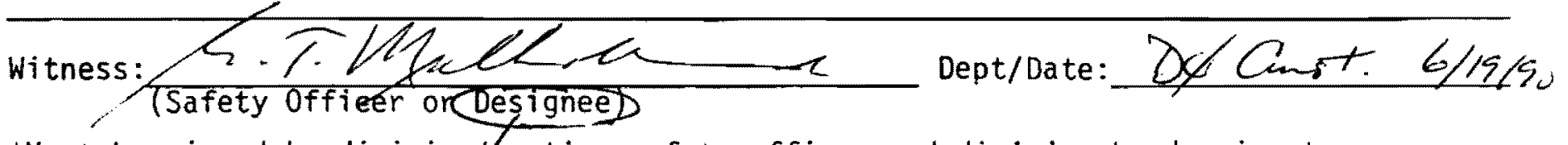

*Must be signed by division/section safety officer and division head prior to conducting test. It is the responsibility of the test coordinator to obtain signatures.

G.T. Mutation..)

p.850

$5034 T A-6$
$6 / 86$ 
SCHEMATIC SETUP FOR PRESSURE TEST EQUIPMENT
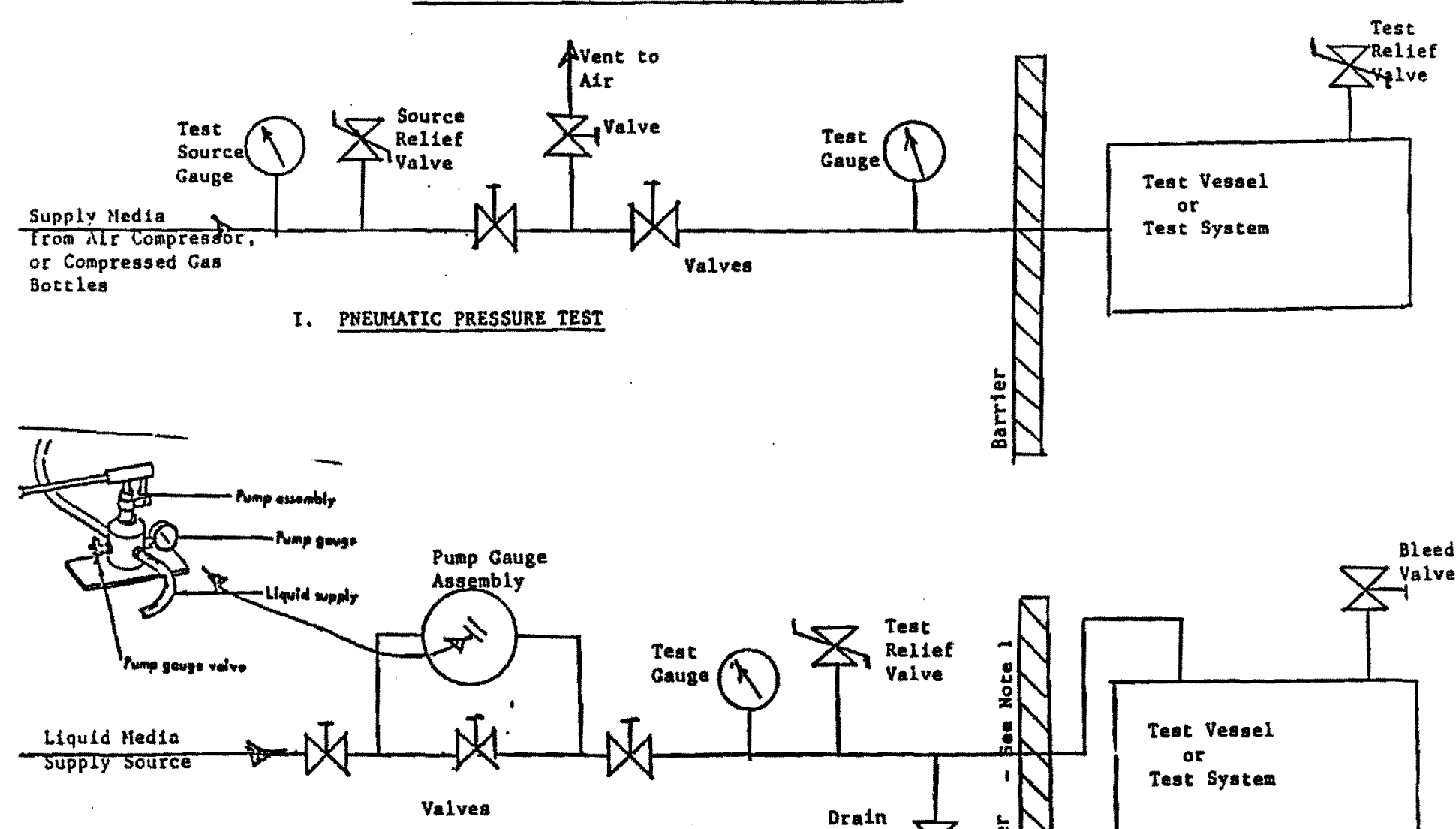

II. HYDROSTATIC PRESSURE TEST

Note 1 - Barricade device maybe necessary for large volume and/or high pressure test vessels.
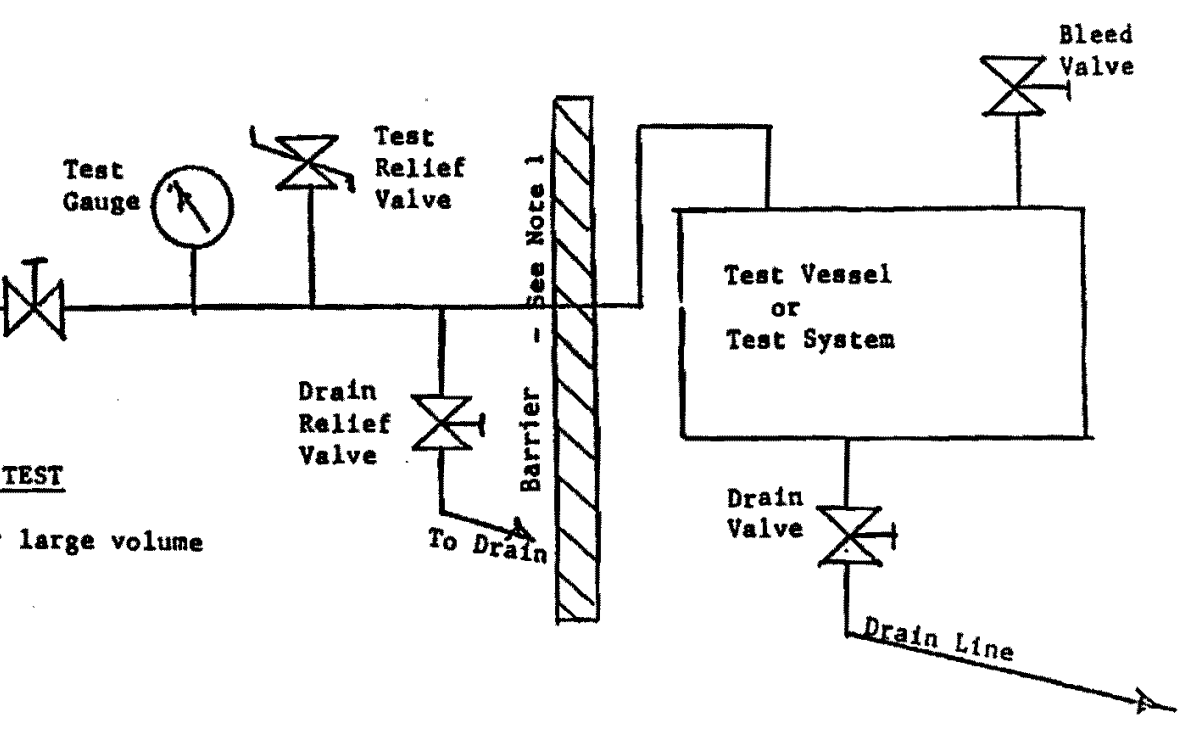